\title{
COMPARATIVE STUDY OF SEVEN BRANDS OF LEVOFLOXACIN 500 MG FILM-COATED TABLET MARKETED IN YEMEN
}

\author{
GAMIL Q. OTHMAN ${ }^{1}$, YASER M. AL-WORAFI ${ }^{1,2}$, MOHAMMED M. BATTAH ${ }^{1 *}$, ABDULSALAM M. HALBOUP ${ }^{1}$, HASSAN \\ M. HASSAN 1
}

1Department of Clinical Pharmacy and Pharmacy Practice, Faculty of Pharmacy, University of Science and Technology, Sana'a, Yemen, ${ }^{2}$ College of Pharmacy, University of Science and Technology of Fujairah, Fujairah, United Arab Emirates

Email: mmalbattah@gmail.com

Received: 10 Nov 2020, Revised and Accepted: 18 Feb 2021

ABSTRACT

Objective: The objective of the current study was to evaluate the quality control parameters of seven brands of levofloxacin 500 mg film-coated tablet available in the Yemeni market.

Methods: Physicochemical parameters assay was performed for seven brands of levofloxacin 500 mg film-coated tablet. Each brand was subjected to official and unofficial in vitro quality control tests, including weight variation, thickness, hardness, friability, disintegration, dissolution, and content uniformity assay by High-Performance Liquid Chromatography (HPLC).

Results: Out of seven, six brands of levofloxacin $500 \mathrm{mg}$ film-coated tablet passed official specified assay tests according to the United States Pharmacopeia (USP) specifications. They showed a similar profile of thickness ranged between \pm 0.01 and $0.10 \%$, friability ranged between $0.01 \%$ and $0.34 \%$, disintegration time ranged between 3.00 and $15.00 \mathrm{~min}$, dissolution percentage ranged between 90.650 and 103.05 and content uniformity ranged between 93.62 and $107.12 \%$. Regarding weight variation and hardness, six brands passed the weight variation test and only three brands showed optimum range (10-20 kg) of hardness test. Only one brand failed to pass the weight variation test, and four brands failed to pass the optimum range $(10-20 \mathrm{~kg})$ of hardness.

Conclusion: There are no remarkable differences between the seven brands regarding in vitro quality control tests of content uniformity, thickness, friability, disintegration, and dissolution. Even though four brands were above the optimum range of hardiness, they showed complete disintegration and dissolution within the acceptable limit. Regular assessment of marketed drugs is required to ensure bioequivalent to their innovators.

Keywords: Levofloxacin, Quality control, Comparative study, Yemeni market

(C) 2021 The Authors. Published by Innovare Academic Sciences Pvt Ltd. This is an open access article under the CC BY license (https://creativecommons.org/licenses/by/4.0/) DOI: https://dx.doi.org/10.22159/ijap.2021v13i2.40217. Journal homepage: https://innovareacademics.in/journals/index.php/ijap

\section{INTRODUCTION}

One of the most prescribed drugs in modern medicine is antibiotics. They are widely used to treat bacterial infections by killing or inhibiting bacteria [1]. Levofloxacin is a synthetic fluoroquinolone agent; it has a broad spectrum to fight different kinds of bacteria in the body of Gram-positive and Gram-negative organisms for oral and intravenous administration. Chemically, it is the pure (-)-(S) enantiomer of the racemic drug substance Ofloxacin. Levofloxacin is widely used in the treatment of bacterial infections of the skin and urinary tract infections, as well as upper and lower respiratory tract infections, such as acute bacterial sinusitis, acute exacerbations of chronic bronchitis, and community-acquired pneumonia [1-3]. A filmcoated tablet has some advantages over other types, as it is covered with a coating to mask the unpleasant odor and taste, to allow the tablet to pass into the small intestine without disintegration in the stomach, and to enhance the stability and strength of the tablet [4].

Biochemical and pharmacological quality control tests for different brands of pharmaceutical products that contain the same active ingredients are vital steps to confirm therapeutic equivalence for such products. Additionally, oral dosage forms depend profoundly on dissolution studies in vitro to predict their bioavailability in vivo $[1,5]$. Furthermore, the official and unofficial quality control tests in vivo-in vitro are required to confirm the safety and efficacy of any pharmaceutical product [6].

In Yemen as well as other poor countries, the price of drugs is the main factor in determining patient's access to health care, where many people put off the use of needed medicines due to the high cost of branded products. Moreover, few studies have been conducted so far to evaluate drugs' quality control in Yemen [6-8]. Therefore, further studies should be conducted in this field to evaluate the quality control tests for locally and internationally manufactured drugs, to ensure the quality and efficacy of the pharmaceutical products, and to offer suitable substitutions to patients.
Even though there are many different brands of levofloxacin available in the Yemeni market and the clinical use of levofloxacin is highly increased among the public, there is no quality control study has been conducted on this field in Yemen. The findings of this study can be used as a source of information to drug regulatory authorities and drug manufacturers in Yemen. Accordingly, this study was aimed to evaluate the quality control of different brands of levofloxacin $500 \mathrm{mg}$ film-coated tablet available in the Yemeni market.

\section{MATERIALS AND METHODS}

\section{Materials}

All materials were purchased from Scharlab S. L. (Scharlau Chemie s. a, Spain) and were supplied by Modern Pharma Pharmaceutical Industry. Trifluoracetic acid, Acetonitrile, Hydrochloric acid $0.1 \mathrm{~N}$, and Ethanol absolute $\geq 99.8 \%$. Distilled water was papered with (PH 7).

\section{Instruments}

HPLC (High-Performance Liquid Chromatography; Waters, model: Pump, 1525, Detector, 2998, Germany) and USP dissolution apparatus paddle method-type II (PHARMA TEST: PTWS 1220, Germany). Other instruments used included a Micrometer for thickness test (Mitutoyo operating manual, Japan), Tablet Hardness Tester (PHARMA TEST: PTB, 111E, Germany), a Friabilator (PHAMA TEST: PTB 10E, Germany), an Electronic balance (KERN and SOHN: ABS 220-4, Germany), and disintegration tester (PHARMA TEST: PTZ S, Germany).

Methods

\section{Study design}

Official and unofficial quality control parameters, including weight variation, thickness, hardness, friability, disintegration time, dissolution profile and content uniformity assay, were studied in 
vitro for comparison between seven commercial brands of levofloxacin $500 \mathrm{mg}$ film-coated tablet available in the Yemeni's market.

\section{Samples collection}

Seven brands of levofloxacin $500 \mathrm{mg}$ film-coated tablet were obtained from different retail pharmacies in Sana'a, Yemen. Study samples were collected from January $20^{\text {th }}$ to February $20^{\text {th }}, 2020$. All of the selected brands of levofloxacin were plain compressed uncoated tablets. The seven brands were checked for their strength, batch number, manufacturing and expiry dates, as well as they, were coded from A to G (table 1). All chemicals used were of Analytical Grade, and the standard procedures were used during all analytical processes. The study samples were stored at $25^{\circ} \mathrm{C}$ according to the manufacturers' instructions before evaluation.

Table 1: List of the tested commercial levofloxacin $500 \mathrm{mg}$ film-coated tablet in Yemen

\begin{tabular}{|c|c|c|c|c|c|c|c|}
\hline Country & Code & Brands & Strength & Manufacturer & Batch No. & Mfg. Date & Exp. Date \\
\hline Argentina & A & Leflumax & $500 \mathrm{mg}$ & Elea S. A. C. I. F. & 5466 & $07 / 2018$ & $07 / 2021$ \\
\hline Egypt & B & Lee-flox & $500 \mathrm{mg}$ & Pharo-Pharma & 1147005 & $05 / 2017$ & $05 / 2020$ \\
\hline Yemen & $\mathrm{C}$ & Levota & $500 \mathrm{mg}$ & RFA-Pharma & 17A275B & $12 / 2017$ & $12 / 2020$ \\
\hline Yemen & $\mathrm{D}$ & Lefoxin & $500 \mathrm{mg}$ & Modern Pharma & 19138 & $02 / 2019$ & $02 / 2022$ \\
\hline Yemen & E & Levomax & $500 \mathrm{mg}$ & Y.E. Pharma & 5466 & $02 / 2019$ & $02 / 2022$ \\
\hline India & $\mathrm{F}$ & Levolab & $500 \mathrm{mg}$ & Laborate pharmaceutical & LLNT-002 & $06 / 2018$ & $05 / 2021$ \\
\hline India & G & Levobact & $500 \mathrm{mg}$ & Cipla ltd. & BA80151 & $12 / 2017$ & $11 / 2020$ \\
\hline
\end{tabular}

\section{Physiochemical parameters measurement}

\section{Thickness test}

Thickness measuring test is necessary to facilitate packaging. To carry out this test, ten tablets from each brand were examined. The mean of each brand was determined in $\mathrm{mm}$ within an acceptable variation of $\pm 5 \%$ of the size of the tablet [9].

\section{Hardness test}

The hardness of tablets is essential to withstand mechanical shocks during the different processes of manufacturing, handling, packaging and transporting. Ten tablets were selected from each brand and subjected to Tablet Hardness Tester. Hardness and mean hardness were calculated for each brand. The minimum adequate value of tablet hardness (crushing strength) is $4 \mathrm{~kg}$ or above, while the optimum hardness for coated tablets is $10-20 \mathrm{~kg}[10,11]$.

\section{Friability test}

Tablet friability is an essential factor for the tablet to withstand attrition in the package container because of chipping and powdering or fragmentation of the tablets during handling and shipping. It can adversely affect the tablet appearance, acceptance, weight variation and content uniformity [12]. Friability test evaluates the impact of transporting tablets from the manufacturer to the point of sale, as no sample is assumed to lose more than $1 \%$ of its weight after testing to withstand rough handling and transportation through potholed roads [13]. In order to carry out this process, twenty tablets of each levofloxacin 500 $\mathrm{mg}$ brand were weighed initially and then subjected to abrasion using a Friabilator. The Friabilator was set to make 100 revolutions in $4 \mathrm{~min}$. Later on, the tablets were removed from the Friabilator and reweighed again after dusting. The friability was calculated by measuring the difference in weight according to the following equation [14]:

$$
\text { Friability }=\frac{\text { Weight before }- \text { Weight after }}{\text { Weight before }} \times 100
$$

The acceptable limit of friability is up to $1 \%$ [15].

\section{Weight variation test}

This test is used to ensure a constant dose of drugs between different brands. Twenty tablets were selected from each brand and weighed using an Electronic balance, then each tablet was weighed individually. The average of weight variations for all brands was calculated.

The weight variation for an individual brand should not exceed $\pm 5 \%$ according to the United State Pharmacopeia (USP) and British Pharmacopeia (BP) standers; to pass, no more than $2 / 20$ tablet differ by more than the percentage permitted and no one tablet differ by more than double the percentage $[11,16,17]$.

\section{Disintegration}

To measure the time required for tablets to breakdown into small particles, the disintegration test was performed by disintegration tester in a medium of $0.1 \mathrm{~N} \mathrm{HCL}$ and a temperature of $37 \pm 1^{\circ} \mathrm{C}$. A disintegration test is carried out using 6 coated tablets according to the USP. The required time for each tablet to disintegrate and pass out through the mesh was recorded, and the mean disintegration time for each brand was then calculated [18].

\section{Dissolution}

The pattern of levofloxacin released over a certain period of time can be determined by the dissolution test. As part of the In vitro-In vivo correlation, all dissolution test parameters should be set to be identical to the human body's conditions [19]. Using the dissolution apparatus, the dissolution medium was prepared with $900 \mathrm{ml}$ of 0.1 $\mathrm{N} \mathrm{HCL}$, and the dissolution process was performed at a temperature of $37 \pm 0.5^{\circ} \mathrm{C}$ and a speed of $75 \mathrm{rpm}$. Furthermore, an amount of $5 \mathrm{ml}$ as samples were withdrawn every $10 \mathrm{~min}$ and replaced with an equal amount of fresh dissolution medium. The obtained samples were subjected to be suitably diluted and analyzed for levofloxacin using HPLC at $294 \mathrm{~nm}$, where the absorbance was measured and the percentage of drug release was determined $[14,20]$.

\section{Content uniformity assay}

The active ingredient uniformity test of the tablets was carried out using HPLC. Diluent and Trifluoroacetic acid were prepared freshly in a ratio of 1000 to 1 were used as the mobile phase; the diluent contains water and acetonitrile in a ratio of 82 to 18 . The flow rate of the mobile phase was $0.7 \mathrm{ml} / \mathrm{min}$, and the injection volume of the sample was $20 \mu \mathrm{l}$. Levofloxacin detection wavelength was set at 294 $\mathrm{nm}$. The acceptable limit for drug content, chemical compliance and content of active ingredients uniformity tests were carried out in accordance with the standard method specified in USP [17].

\section{Data analysis}

Tablets' weight variation, content uniformity, hardness, friability, thickness, disintegration, and dissolution tests were analyzed by calculating the mean \pm standard deviation (SD) for each test using IBM SPSS Statistics version 21.0 for Windows (IBM Corp., Armonk, NY, USA).

\section{RESULTS}

\section{Thickness, friability, and hardness of levofloxacin brands}

Thickness, friability, and hardness results among all brands are summarized in table 2. Among all brands, the average thickness of the seven brands was ranged between \pm 0.01 and $0.10 \%$. Out of seven, four brands failed to pass the optimum range of hardness. The friability test among all brands was ranged from $0.01 \%$ to $0.34 \%$; the highest value was found with brand $\mathrm{E}$. The maximum crushing strength was found in brand $\mathrm{C}\left(25.76 \mathrm{~kg} / \mathrm{cm}^{2}\right)$, while the lowest one was found in brand $A\left(17.33 \mathrm{~kg} / \mathrm{cm}^{2}\right)$. 
Table 2: Thickness, friability, and hardness for seven brands of levofloxacin $500 \mathrm{mg}$ film-coated tablets

\begin{tabular}{llll}
\hline Code & Hardness $\left(\mathbf{k g} / \mathbf{c m}^{\mathbf{2}}\right)(\mathbf{n = 1 0})$ & Friability $(\mathbf{w} / \mathbf{w})(\mathbf{n}=\mathbf{2 0})$ & Thickness $(\mathbf{m m})(\mathbf{n}=\mathbf{1 0})$ \\
\hline A & $17.33 \pm 0.6$ & $0.01 \pm 0.02$ & $5.3491 \pm 0.01$ \\
B & $25.34 \pm 1.7$ & $0.29 \pm 0.01$ & $5.5544 \pm 0.01$ \\
C & $25.76 \pm 4.92$ & $0.01 \pm 0.04$ & $5.8651 \pm 0.03$ \\
D & $18.50 \pm 1.0$ & $0.01 \pm 0.04$ & $5.2357 \pm 0.10$ \\
E & $21.72 \pm 1.0$ & $0.34 \pm 0.02$ & $5.4549 \pm 0.04$ \\
F & $19.98 \pm 3.32$ & $0.09 \pm 0.06$ & $5.5501 \pm 0.01$ \\
G & $21.97 \pm 1.0$ & $0.01 \pm 0.06$ & $5.2581 \pm 0.04$ \\
Limits & $10-20 \mathrm{~kg} / \mathrm{cm}^{2}$ & $<1 \%$ & $\pm 5 \%$ \\
\hline
\end{tabular}

Data given in each reading as mean \pm SD (SD: Standard Deviation)

\section{Official quality control parameters results}

Weight variation, disintegration time, dissolution time, and content uniformity of levofloxacin brands results are summarized in table 3 . Mean weight of the seven brands was ranged between $623.1 \pm 10.8$ for brand $E$ and $968.8 \pm 27.7$ for brand $F$, and the weight range for all seven brands was $69 \%-73 \%$ of the mean weight, whereas it was 70 -
$80 \%$ for brand C. Mean disintegration time for all brands was ranged between 3.00 to $15.00 \mathrm{~min}$. The mean dissolution time percentage was ranged from 90.650 to 103.05 , while the content uniformity for all brands was ranged from 93.62 for brand $\mathrm{C}$ to $107.12 \%$ for brand E. All brands were compliant with quality control parameters according to USP specification except weight variation, where one brand did not pass the weight variation test.

Table 3: Official quality control parameters for seven brands of levofloxacin $500 \mathrm{mg}$ film-coated tablets

\begin{tabular}{|c|c|c|c|c|c|}
\hline \multirow[t]{2}{*}{ Code } & \multicolumn{2}{|c|}{ Weight variation } & \multirow{2}{*}{$\begin{array}{l}\text { Content uniformity } \\
(\%)(n=20)\end{array}$} & \multirow{2}{*}{$\begin{array}{l}\text { Disintegration time } \\
(\mathrm{min})(\mathrm{n}=6)\end{array}$} & \multirow{2}{*}{$\begin{array}{l}\text { Dissolution time \% } \\
\text { (after } 30 \mathrm{~min})(\mathrm{n}=6)\end{array}$} \\
\hline & $(\mathrm{mg})(\mathrm{n}=20)$ & (range $\%$ from mean) & & & \\
\hline $\mathrm{A}$ & $623.4 \pm 2.4$ & $62-63$ & $100.48 \pm 0.450$ & $11.00 \pm 0.018$ & $100.71 \pm 3.22$ \\
\hline $\mathrm{B}$ & $650.7 \pm 5.1$ & $64-66$ & $99.51 \pm 0.267$ & $6.00 \pm 0.026$ & $90.650 \pm 1.72$ \\
\hline $\mathrm{C}$ & $755.3 \pm 25.5$ & $70-80$ & $93.62 \pm 0.663$ & $15.00 \pm 0.087$ & $99.640 \pm 0.65$ \\
\hline $\mathrm{D}$ & $723.2 \pm 5.8$ & $71-73$ & $99.91 \pm 0.461$ & $3.00 \pm 0.025$ & $100.49 \pm 2.70$ \\
\hline $\mathrm{E}$ & $623.1 \pm 10.8$ & $61-64$ & $107.12 \pm 0.141$ & $8.00 \pm 0.076$ & $100.62 \pm 1.19$ \\
\hline $\mathrm{F}$ & $968.8 \pm 27.7$ & $92-102$ & $105.01 \pm 0.070$ & $12.00 \pm 0.028$ & $103.05 \pm 0.53$ \\
\hline $\mathrm{G}$ & $657.0 \pm 4.0$ & $64-66$ & $105.03 \pm 0.649$ & $7.00 \pm 0.021$ & $100.86 \pm 1.51$ \\
\hline Limits & & \pm 5 & $90-110 \%$ & 30 & $>80 \%$ \\
\hline
\end{tabular}

Data given in each reading as mean \pm SD (SD: Standard Deviation)

\section{DISCUSSION}

To the best of our knowledge, this study was conducted as the first one to evaluate official and unofficial quality control parameters of different brands of levofloxacin $500 \mathrm{mg}$ film-coated tablets that were available on the Yemeni market.

The uniformity in the thickness of tablets was pivotal for tablets' packaging and consumers' requirements [21]. Our findings showed that the variation of tablets' thickness was within the accepted limit; $\pm 5 \%$, where it was ranged between \pm 0.01 and $0.10 \%$. In agreement with our findings, a previous study revealed the closeness of all filmcoated tablets' thickness, where the standard deviation was found between 0.02-0.06 [22].

According to USP, the satisfactory limit of friability is not greater than $1 \%$ [17]. Our findings of all levofloxacin brands were in agreement with the USP standers and fulfill this criterion to confirm the mechanical stability of all brands. Additionally, this finding was in agreement with previous studies conducted on different brands of levofloxacin $250 \mathrm{mg}$ and ciprofloxacin $500 \mathrm{mg}$, where they revealed that tablets with the highest value of hardness showed a low friability value $[2,7]$.

Regarding weight variation, when the strength of the active ingredient is greater than $324 \mathrm{mg}$ in a tablet, its weight variation fulfills the requirements if the mean weight of each brand does not deviate by more than $\pm 5 \%$ as recommended by USP [17]. The finding of the current study showed that out of seven, six brands (A, B, D, E, $F$ and G) were passed the USP specifications, while brand $C$ did not comply with the USP specifications. The most logical explanation for the discrepancy in the average weight between different products might be attributed to the differences in the excipients and technique during manufacturing. Additionally, the variations of weight might be attributed to the improper tooling sets and poor granulation flow properties during formulation. The variation in the tablet's weight might cause variances in the tablet's size that play an important role in the compliance of patients. A comparable study conducted in Pakistan showed remarkable variations in the weight of levofloxacin tablets $250 \mathrm{mg}$; however, such variations are meaningless as long as the tablet thickness is adjusted accordingly [1].

Additionally, other previous studies revealed that weight variation of the tablet dosage form is also being indicative of the uniformity of drug contents, as any weight variation obviously reflects variation in the content of active pharmaceutical ingredients [23-25]. In our study, all the seven brands of levofloxacin, even brand $C$ that did not pass the weight uniformity test, were displayed an acceptable range of drug contents as specified by USP; between $90 \%$ and $110 \%$ [17]. The slight differences in drug contents among levofloxacin brands may be attributed, in part, to the non-uniform weight of active ingredients or poor storage conditions during the manufacturing process and shipping.

Tablet hardness depends on the weight of the used materials, the nature and quantity of additives or binders used during formulation, and the force of the applied pressure during compression. It, in turn, influences friability, disintegration time, and drug dissolution, which may affect drug bioavailability. Hard tablet hinders the disintegration process, while the soft tablet cannot resist handing during packing and shipping. In the current study, Out of seven, four brands failed to pass the optimum range of hardness; however, their disintegration and dissolution, as well as friability, did not affect accordingly. The reasons behind such a high hardness value might be attributed to the nature, quantity, and the force of compression that was utilized during the manufacturing process [26]. As a result, the high value in hardness making the products able to withstand mechanical shocks during manufacturing, handling, packaging, and transportation processes. This finding was in line with a previous study conducted on metformin tablets, which concluded that the crushing strength of the products was above the satisfactory limit; however, they showed no impact on disintegration [22]. Another 
review article emphasized that if the tablet's hardness is too high, it is essential firstly to check its disintegration before rejection. It stated that as long as the disintegration is within acceptable limits, the drug will be accepted and approved [27].

Besides, disintegration refers to the breakup of a tablet into smaller granules, which is an essential process for dissolution and absorption as well as efficacy [28]. According to USP, the disintegration time limit is not to be more than $30 \mathrm{~min}$ for uncoated and film-coated tablets. In the present study, all seven brands passed the USP-specific criteria. The discrepancies in the rate of disintegration of all brands might attribute, in part, to the excipients, the physicochemical properties of the active ingredients, the manufacturing procedure, and the amount used of disintegrant [6].

Regarding the dissolution rate, it is required as a pivotal criterion for drug bioavailability to confirm the drug release pattern of the dosage form [19]. All brands in the current study released their active contents in a range of $90.65 \%$ to $103.05 \%$ within the allowed time as specified by USP.

Compared to the general findings of this study, previous studies performed on levofloxacin $250 \mathrm{mg}$ in Pakistan and India confirmed that all the brands of levofloxacin $250 \mathrm{mg}$ showed satisfactory results regarding the physicochemical parameters tested as the USP specifications $[1,2]$. Moreover, another comparable study conducted in Nigeria showed that $60 \%$ of the levofloxacin $500 \mathrm{mg}$ tablet brands failed at least in one of the quality control parameters tests, whereas only $40 \%$ of the brands passed both physicochemical and bioequivalence tests, and they were interchangeable [29].

\section{CONCLUSION}

The findings of this study are clearly demonstrated that all seven brands of levofloxacin $500 \mathrm{mg}$ film-coated tablet, whether manufactured locally or in other countries, exhibited similar profiles to each other in terms of drug content uniformity, disintegration, dissolution, friability, and thickness tests, as well as uniformity test of weight variation for sex brands. Although four studied brands were above the optimum range of hardness, they showed complete disintegration and dissolution within the acceptable limit of USP standards. Particularly, these findings probably help to reinforce the feeling of shared trust between physicians and patients about locally and internationally manufactured medicines. Regular assessment of marketed drugs is required to ensure bioequivalence to their innovators.

\section{ACKNOWLEDGMENT}

The authors acknowledge the $5^{\text {th }}$-year pharmacy students at the University of Science and Technology, 2020-2021, Sana'a, as well as the Modern Pharma Company for the pharmaceutical industry, Yemen for their help during the performance of the study.

\section{FUNDING}

Nil

\section{AUTHORS CONTRIBUTIONS}

All the authors have contributed equally.

\section{CONFLICT OF INTERESTS}

The authors declare that they have no competing interests.

\section{REFERENCES}

1. Bano R, Gauhar S, Naqvi SBS, Mahmood S. Pharmaceutical evaluation of different brands of levofloxacin tablets $(250 \mathrm{mg})$ available in local market of Karachi (pakistan). Int J Curr Pharm Res 2011;3:15-22.

2. Poornachandra TM, Prudviraj A, Robinah K, Roy A, Sivasubramanian L. Comparative in vitro bioavailability studies on different brands of levofloxacin tablets. Acta Sci Pharm Sci 2019;3:50-4.

3. Kumar TM, Srikanth G, Rao JV, Rao K. Development and validation of HPLC-UV method for the estimation of levofloxacin in human plasma. Int J Pharm Pharm Sci 2011;3:247-50.

4. Katakam L. Split-half tablets: a complete review for analytical testing. Asian J Pharm Clin Res 2019;12:27-38.

5. Dressman JB, Amidon GL, Reppas C, Shah VP. Dissolution testing as a prognostic tool for oral drug absorption: immediate release dosage forms. Pharm Res 1998;15:11-22.

6. Alsaifi A. Comparative evaluation quality of different brands of ibuprofen $400 \mathrm{mg}$ tablets available in yemeni's market. Chronicle Pharm Sci 2018;2:724-36.

7. Alyahawi A, Abdulmajed A. Quality control assessment of different brands of ciprofloxacin $500 \mathrm{mg}$ tablets in yemen. Univ J Pharm Res 2018;3:31-6.

8. Al-kershi FA, Othman GQ, Al-qadasi FA. Quality and stability of amoxicillin-potassium clavulanate drugs marketed in yemen: Influence of tropical storage conditions. J Chem Pharm Res 2016;8:160-16.

9. Chavan H, Chhabra G, Gujarathi N, Jadhav A. Comparative study of in-process and finished products quality control test for tablet and capsules according to pharmacopoeias. Asian J Pharm Res Dev 2018;6:60-8.

10. Deshpande RD, Gowda D, Mahammed N, Maramwar DN. Bilayer tablets-an emerging trend: a review. Int J Pharm Sci Res 2011;2:25-34.

11. Hammami MM, Hussein RF, AlSwayeh R, Alvi SN. Eight entericcoated $50 \mathrm{mg}$ diclofenac sodium tablet formulations marketed in saudi arabia: in vitro quality evaluation. BMC Res Notes 2020;13:1-6.

12. Amin M, Rahman M. Study and impact evaluation of particle size distribution on physicochemical properties of three different tablet formulations through sieve technology. Int J Pharm Res Scholars 2014;3:448-63.

13. Guetchueng ST, Nnanga E. Quality control evaluation of brands of mebendazole $100 \mathrm{mg}$ tablets on the illegitimate pharmacy outlets. Int J Pharm Pharm Sci 2014;6:355-7.

14. Kalakuntla R, Veerlapati U, Chepuri M, Raparla R. Effect of various super disintegrants on hardness, disintegration and dissolution of drug from the dosage form. J Adv Sci Res 2010;1:15-9.

15. Lachman L, Lieberman A. The theory and practice of industrial pharmacy. Indian ed. New Delhi: CBS Publication and Distributors; 2009. p. 67-8.

16. Commission BP, Council GM, Commission GBM. British pharmacopoeia. London: Her Majesty's Stationery Office; 2013.

17. United State Pharmacopeia and National Formulary USP 39-NF 34; The United States Pharmacopeial Convention, Inc: Rockville MD; 2016 .

18. Gangwar S, Singh S, GarDFg G, Garg V, Sharma P. To compare the disintegrating property of papaya starch and sago starch in paracetamol tablets. Int J Pharm Pharm Sci 2010;2 Suppl 2:148-51.

19. Ali BA, Al-haddad MG, Areqi AA. Comparative evaluation of some commercial clopidogrel tablets available in yemen. Majalah Farmaseutik 2017;13:79.

20. Logoyda L, Kovalenko S, Abdel Megied AM, Zhulkevych I, Drapak I, Demchuk I, et al. Hplc method development for the analysis of bisoprolol in a combined dosage form containing bisoprolol and enalapril and in vitro dissolution studied. Int J Appl Pharm 2019;11:186-94.

21. Nigatu M, Mohammed F, Temesgen A. In vitro comparative study of different brands of pantoprazole sodium entericcoated tablets marketed in addis ababa, ethiopia. Asian J Pharm Res Dev 2019;7:13-8.

22. Abatea $\mathrm{K}$, Temesgen $\mathrm{A}$, Nigatu $\mathrm{M}$. Comparative in vitro evaluation of different brands of metformin hydrochloride film coated tablets marketed in addis ababa, ethiopia. Asian J Pharm Res Dev 2020;8:44-50.

23. Jakaria M, Mousa A, Parvez M, Zaman R, Sayeed M, Ali M. In vitro comparative study of different brands of dexamethasone tablet available in bangladesh. Int J Pharm Qual Assur 2016;7:24-8.

24. Sultana S, Hosen MS. In vitro comparative quality evaluation of different brands of esomeprazole tablets available in selected community pharmacies in dhaka, bangladesh. BMC Res Notes 2018;11:184. 
25. Desta HK, Teklehaimanot TT. In vitro quality evaluation of generic ciprofloxacin tablets available in community pharmacies of dessie town, northeast ethiopia. J Generic Med 2020;1:1-8.

26. Kumar P, Ganure AL, Subudhi BB, Shukla S, Upadhyay P. Design and comparative in vitro and in vivo evaluation of starch-acrylate graft copolymer-based salbutamol sulphate sustained release tablets. Asian J Pharm Sci 2015;10:239-46.
27. Kumar D, Singh J, Antil M, Kumar V. Quality control of tablets: a review. Int J Univers Pharm Bio Sci 2016;5:53-167.

28. Giri TK. Comparative in vitro evaluation of conventional ibuprofen marketed formulation. J Pharm Sci Technol 2013;2:75-80

29. Azubuike CP, Oluyase S. Physicochemical and bioequivalence studies on some brands of levofloxacin tablets registered in nigeria. Br J Pharm Res 2014;4:1976-87. 